\title{
Fe-bearing Clay Mineral: A Significant Fe Pool for Abiotic Electron Transfer
}

\section{Zhaohui Wang}

State Environmental Protection Engineering Center for Pollution Treatment and Control in Textile Industry, College of Environmental Science and Engineering, Donghua University, Shanghai, China

*Corresponding author: Zhaohui Wang, editorial board member, Associate professor, College of Environmental Science and Engineering, Donghua University, 201620, China, E-mail: zhaohuiwang@dhu.edu.cn

Rec date: June 12, 2014, Acc date: June 16, 2014, Pub date: June 20, 2014

*Copyright: @ 2014 Zhaohui W. This is an open-access article distributed under the terms of the Creative Commons Attribution License, which permits unrestricted use, distribution, and reproduction in any medium, provided the original author and source are credited.

\section{Editorial}

Clay minerals, which totally make up $4-5 \%$ of the earth's crust, are generally classified into three different phyllosilicate: illites, smectites and kaolins. Of these, kaolin generally has the lowest Fe content and illite the highest; however, smectite also has appreciable Fe contents $(<30 \mathrm{wt} \%)$. In this editorial, the focus is restricted to the Fe-bearing smectites, since smectites are ubiquitous in diverse environments such as soils, sediments and non-marine weathering environments [1].

Iron may exist in both the octahedral and tetrahedral sheets of 1:1 (one octahedral sheet linked to one tetrahedral sheet) and 2:1 (one octahedral sheet sandwiched between two tetrahedral sheets) clay minerals. Iron can also occur as a interlayer compensating ion. Since clay mineral bound $\mathrm{Fe}^{\mathrm{III}}$ is not susceptible to reductive dissolution as Fe oxides are, Fe in clay minerals has been proposed to act as renewable source of redox equivalents in anoxic environment. The structural $\mathrm{Fe}^{\mathrm{III}} / \mathrm{Fe}^{\mathrm{II}}$ couple in clay lattice is a significant redox buffer in many subsurface environments that influences the biogeochemical dynamics of other redox-active elements (e.g. uranium, chromium and arsenic) and nutrient (e.g. phosphate and nitrogen), and contaminants transformation. Much is known that structural FeII is the predominant reductant of a variety of organic and inorganic contaminants [2,3], such as nitroaromatic, chlorinated solvents, chloroacetanilide herbicides, radionuclides and heavy metals. In contrast, $\mathrm{Fe}^{\mathrm{III}}$-bearing clays can catalyze the oxidation of pentachlorophenol to octachlorodibenzodioxin (OCDD) under environmental conditions, explaining the unique dominance of one polychlorinated dibenzo- $p$ dioxins (PCDDs) congener in soils.

Iron redox activity varies for different smectites as a consequence of mineral properties such as total Fe content and cations distribution within the structure, and local binding environments (e.g. aqueous, complexed, sorbed and structural Fe). Previous work has emphasized that not all $\mathrm{Fe}^{\mathrm{II}}$ in smectite is similarly reactive. Hofstetter, et al [2]. demonstrated that basal surface-bound $\mathrm{Fe}^{\mathrm{II}}$ was not reactive toward nitroaromatic, while edge-complexed and structural $\mathrm{Fe}^{\mathrm{II}}$ were effective in producing the aniline products [2]. Chemical reduction of structural $\mathrm{Fe}^{\mathrm{II}}$ in the clay by dithionite is a common "recharge" mode to attain the redox cycling of $\mathrm{Fe}^{\mathrm{III}} / \mathrm{Fe}^{\mathrm{II}}$. Recently, Zhao et al. and our group [4-7] developed a novel photochemical "recharge" method based on the principle of dye photosensitization. Song et al. reported that structural $\mathrm{Fe}^{\mathrm{III}}$ can be in-situ reduced by the excited dyes, providing a sustainable way to revive structural $\mathrm{Fe}^{\mathrm{II}}$ [4]. The photochemically generated structural FeII is efficient to catalyze $\mathrm{H} 2 \mathrm{O} 2$ decomposition [4-6] or reduce toxic $\mathrm{Cr}(\mathrm{VI})$ [7]. Its efficiency can be further enhanced if a synthetic iron-rich smectite (24.4 wt \%) is used [6]. This new strategy to maintain high iron redox activity will be valuable for developing novel Fenton-like reaction or technology for simultaneous removal of dye pollutants and other redox-active metal pollutants.

To date, although much is known about the important role of $\mathrm{Fe}$ pool of clays in biogeochemistry and contaminant transformation, there are still lots of challenges and unanswered questions about the mechanisms governing the electron transfer. For example, how is the electron passed from the reducing agent to Fe atom at the octahedral sheet which is located at a distance of several $\AA$ from the point of closest approach (basal surface)? Why cannot dissimilatory Fereducing bacteria and chemicals like hydrazine, hydroquinone, sulfide and ascorbic acid completely reduce the structural $\mathrm{Fe}^{\mathrm{III}}$ ? Are the all structural $\mathrm{Fe}$ in smectite reactive? In recognition of these challenges, this editorial is a call for additional research to reveal the significance and working principle of Fe-bearing clays as Fe pool for abiotic electron transfer.

\section{Acknowledgement}

This work was financially supported by National Natural Science Foundation of China (NSFC) (Grant Nos. 21007009, 41273108) and Fundamental Research funds for Central Universities Central (2232013A3-08).

\section{References}

1. Stucki JW (1988) In Iron in Soils and Clay Minerals: Stucki JW, GoodmanBA, Schwertmann U. (Edtrs), D. Reidel: Dordrecht, Netherlands.

2. Hofstetter TB, Neumann A, Schwarzenbach RP (2006) Reduction of nitroaromatic compounds by $\mathrm{Fe}(\mathrm{II})$ species associated with iron-rich smectites. Environ Sci Technol 40: 235-242.

3. Yang J, Kukkadapu RK, Dong H, Shelobolina ES, Zhang J, et al. (2012) Effects of redox cycling of iron in nontronite on reduction of technetium. Chem Geol 291: 206-216.

4. Song W, Cheng M, Ma J, Ma W, Chen C, et al. (2006) Decomposition of hydrogen peroxide driven by photochemical cycling of iron species in clay. Environ Sci Technol 40: 4782-4787.

5. Wang Z, Ma W, Chen C, Zhao J (2009) Light-assisted decomposition of dyes over iron-bearing soil clays in the presence of $\mathrm{H}_{2} \mathrm{O} 2$. J Hazard Mater 168: 1246-1252.

6. Liu R, Xiao D, Guo Y, Wang Z, Liu J (2014) A novel photosensitized Fenton reaction catalyzed by sandwiched iron in synthetic nontronite. RSC Adv 4: 12958-12963.

7. Liu R, Guo Y, Wang Z, Liu J (2014) Iron species in layered clay: efficient electron shuttles for simultaneous conversion of dyes and $\mathrm{Cr}(\mathrm{VI})$. Chemosphere 95: 643-646. 